\title{
Pharmacological Effects of Urocortin (Ucn) on Nicotine-Induced Oxidative Stress to Cardiomyocytes
}

\author{
Keiichi lkeda1,2, Yoshinobu Manome ${ }^{1}$, and Katsuyoshi Tojo 2,3 \\ Core Research Facilities for Basic Science ( ${ }^{1}$ Division of Molecular Cell Biology), Research Center for Medical Sciences \\ 2Institute of Clinical Medicine and Research \\ ${ }^{3}$ Division of Diabetes and Endocrinology, Department of Internal Medicine \\ The Jikei University School of Medicine
}

\section{OBJECTIVES}

\section{Background:}

One of the cytotoxic actions of nicotine is oxidative stress ${ }^{1}$. Recently, it is repoted that corticotropin-releasing hormone $(\mathrm{CRH})$ related peptide, urocortin (Ucn) I, protects cultured hippocampal neurons and human umbilical endothelial cells against oxidative stress ${ }^{2}, 3$

The aim(s) of this present study:

To clarify the effects of Ucn I against nicotine-induced oxidative stress in cardiomyocytes.

Through which mechanism Ucn I exerts anti-oxidative stress in cardiomyocytes.

\section{METHODS}

- HL-1 caridomyocytes (mouse atrial cardiomyocyte cell line, gift from Prof. William C Claycomb, LSU Health Sciences Center, New Orleans, LA, USA)

- ROS assay (quatification \& imaging)

- Agents: urocortin I/II, (+/-)-nicotine, $\mathrm{H}_{2} \mathrm{O}_{2}$

- Ucn I siRNA: siRNA designed by BLOCK-iT'TM RNAi Designer (Thermofischer Scientific, Inc.)

ROS iquantification/maging:

1. Cells are plated in 96-well plate.

2. Culture with Claycomb medium containing $10 \%$ fetal bovine serum (FBS) for 48 hours.

3. FBS starvation for 24 hours.

4. Quantification :Loading of 2', 7'-Dichlorodihydrofluorescin diacetate (DCFH-DA) to the cells for 1 hour prior to stiumulation.

5. Stimulation with or without above mentioned agents.

6. Quantification: 12 hour after stimulation, conversion of DCFH-DA to 2', 7'-dichlorodihydrofluorescein (DCF) was measured.

7.Imaging: Dihydroethidium was loaded to the cardiomyocytes 30 min prior to complete 24 hour incubation.

\section{SUMMARY OF RESULTS}

1. Ucn I exerted antioxidative actions against $\mathrm{H}_{2} \mathrm{O}_{2}-/(+/-)-$ nicotine-induced oxidative stress.

2.Ucn I, but not Ucn II, exerted antioxidative actions in dose-dependent manner in the stimulant-free culture condition.

3. Knockdown of Ucn I mRNA resulted in increase in nicotine-induced oxidative stress.

4. Ucn II may reduce (+/-)-nicotine-induced anti-oxidative stress.
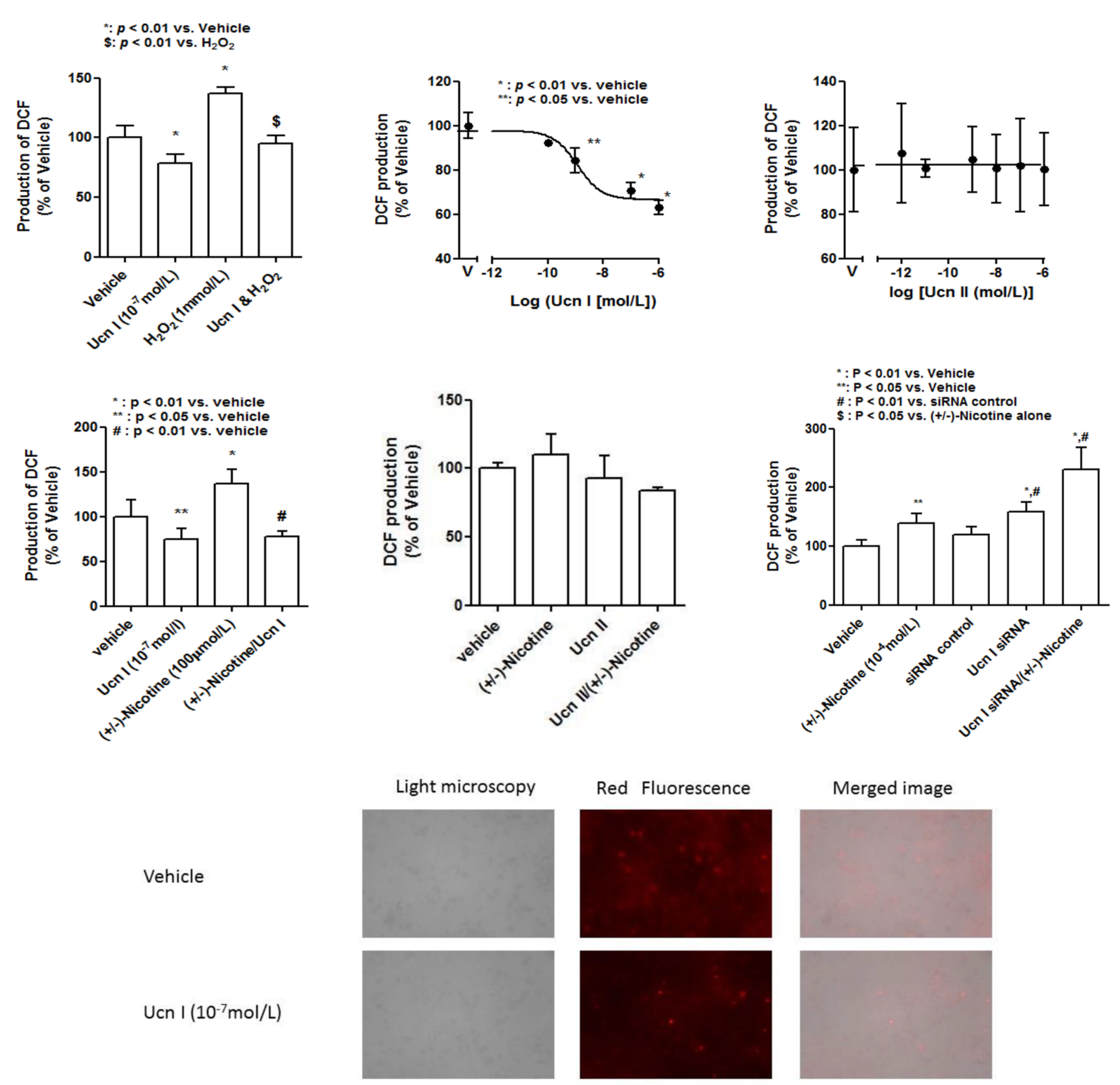

$\operatorname{Ucn~I~(10-7~} \mathrm{mol} / \mathrm{L})$
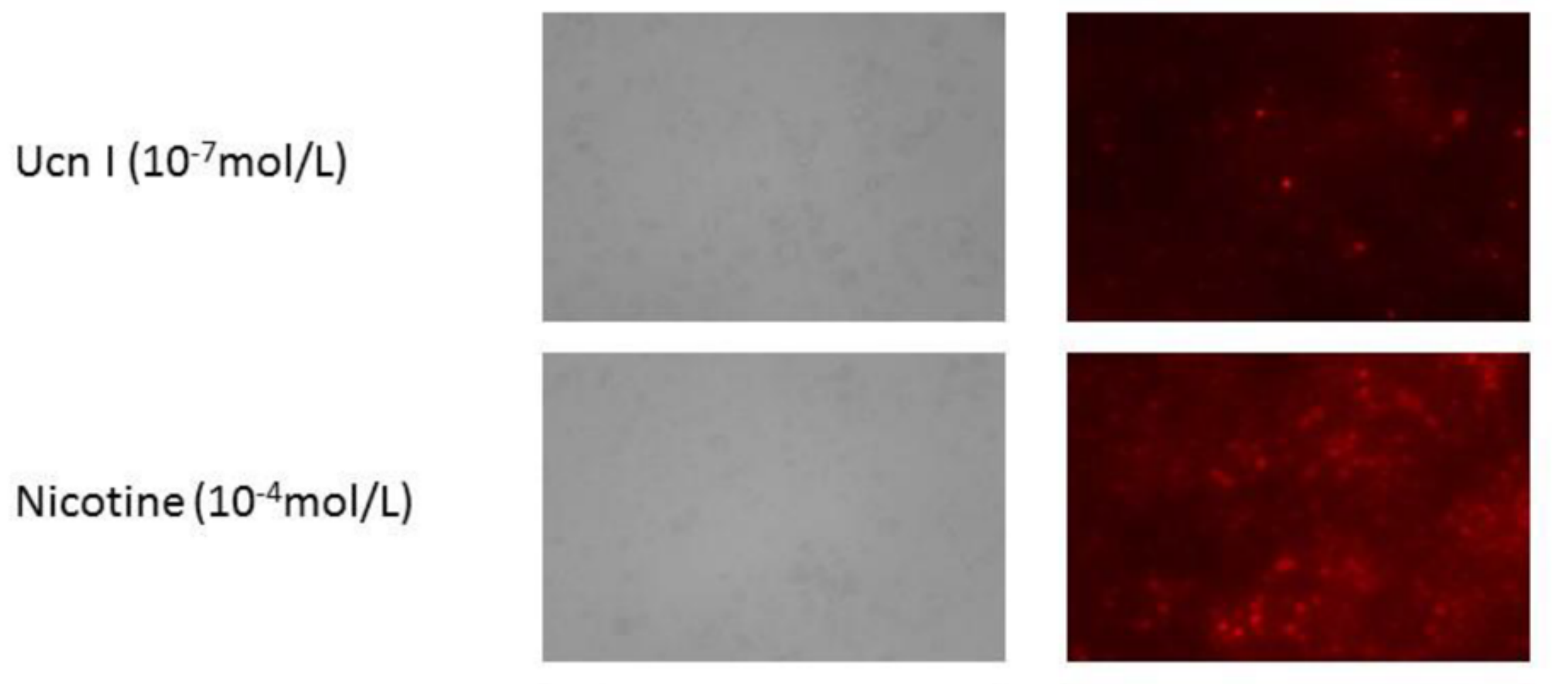

Nicotine $\left(10^{-4} \mathrm{~mol} / \mathrm{L}\right)$

Ucn I (10-7 $\mathrm{mol} / \mathrm{L})$
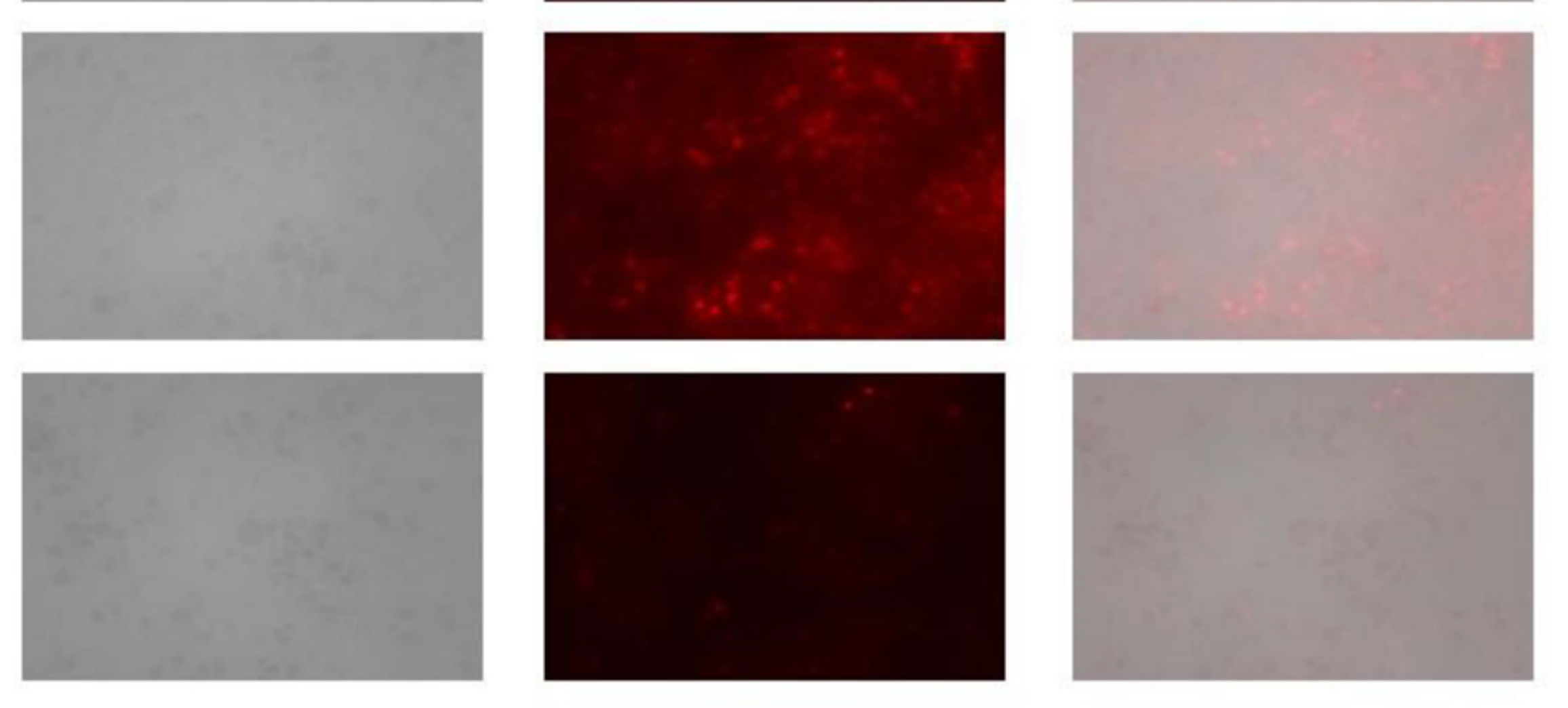

\section{CONCLUSIONS}

1.Ucn I may have anti-oxidative stress against denovosynthesized and oxidant-induced oxidative stress.

2.Knockdown of Ucn I mRNA resulted in increase in oxidative stress, indicating that Ucn I may play essential roles on cell protection in $\mathrm{HL}-1$ cardiomyocytes.

3. Ucn II did not exert antioxidative stress in stimulant-free HL-1 cardiomyocyte culture, whereas Ucn II may exert antioxidative stress against nicotine-induced oxidative stress, indicating that the mechanisms of anti-oxidative actions by these peptides may be defferent in spite of same receptor agonists.

\section{References}

1. Howard DJ, Briggs LA, Pritos CA. Oxidative DNA damage in mouse heart, liver, and lung tissue due to acute side stream tabacco smoke exposure. Arch Biochem Biophys 1998; 352: 293 $-297$

2.Pedersen WA, Wan $\mathrm{R}$, Zang $\mathrm{P}$, et al. Urocortin, but not urocortin II, protects cultured hippocampal neurons from oxidative and excitotoxic cell death via corticotropin-releasing hormone receptor type I. J Neurosci 2002; 22: $404-412$ 3.Honjo T, Inoue N, Shiraki R, et al. Endothelial urocortin has antioxidative properties and is upregulated by inflammatory cytokines and pitavastatin. J Vasc Res 2006; 43: 131 - 138

The present study was supported by the grant from Smoking Research Foundation. 